\title{
Influence of Specific Contributing Area algorithms on slope failure prediction in landslide modeling
}

\author{
J.-C. Huang ${ }^{1}$, S.-J. Kao ${ }^{1}$, M.-L. Hsu ${ }^{2}$, and Y.-A. Liu ${ }^{3}$ \\ ${ }^{1}$ Research Center for Environmental Changes, Academia Sinica, Taipei, Taiwan \\ ${ }^{2}$ Department of Geography, National Taiwan University, Taipei, Taiwan \\ ${ }^{3}$ Center for Space and Remote Sensing Research, National Central University, Taoyuan, Taiwan
}

Received: 4 July 2007 - Revised: 22 November 2007 - Accepted: 22 November 2007 - Published: 6 December 2007

\begin{abstract}
This study anatomized algorithm effects of specific contributing area (SCA) on soil wetness estimation, consequently landslide prediction, in SHALSTAB. A subtropical mountainous catchment during three typhoon invasions is targeted. The peak 2-day rainfall intensity of the three typhoons: Haitang, Mindulle and Herb are 144, 248 and $327 \mathrm{~mm} /$ day, respectively. We use modified success rate (MSR) to retrieve the most satisfying mean condition for model parameters in SHALSTAB at three rainfall intensities and respective pre-typhoon NDVI themes. Simulation indicates that algorithm affects the prediction of landslide susceptibility (i.e. FS, Factor of Safety) significantly.
\end{abstract}

Based on fixed NDVI and the mean condition, we simulate by using full scale rainfall intensity from 0 to $1200 \mathrm{~mm} /$ day. Simulations show that predicted unstable area coverage increases non-linearly as rainfall intensity increases for all algorithms yet with different increasing trends. Compared to Dinf, D8 always gives lower coverage of predicted unstable area during three typhoons. By contrast, FD8 gives higher coverage areas. The absolute difference (compared to Dinf) in predicted unstable area ranges from $\sim-3 \%$ to $+4 \%$ (percent watershed area). The relative difference (compared to Dinf) ranges from $-15 \%$ to as high as $+40 \%$. The maximum absolute and relative differences in unstable area prediction occur around the condition of $100-300 \mathrm{~mm} /$ day, which is common in subtropical mountainous region.

Theoretical relationship among slope, rainfall intensity, SCA and FS value was derived in which FS values are very sensitive to algorithms in the field of slope from 37 to 52degree. Results imply any comparison among SCA-related landslide models or engineering application of rainfall return period analysis must base on the same algorithm to obtain comparable results. This study clarifies the SCA algorithm effect on FS prediction and deepens our understanding on landslide modeling.

Correspondence to: S.-J. Kao

(sjkao@gate.sinica.edu.tw)

\section{Introduction}

Among hydro-geomorphic processes, rainfall-induced shallow landslide is a threatening hazard in many mountainous watersheds around the world. Deterministic landslide models are widely applied to construct landslide susceptibility maps for management and hazard mitigation (Montgomery and Dietrich, 1994; Wu and Sidle, 1995; Burton and Bathurst, 1998; Borga et al., 1998; Pack et al., 1998). Previous studies have proven that soil wetness caused by rain storms plays a crucial role in triggering landslides. However, it is difficult to obtain accurate measurements of soil wetness during storm periods within the entire watershed. Accordingly, estimation of soil wetness by hydrologic models is widely applied, which is then coupled into landslide models. Soil wetness is usually obtained through calculation of slope and specific contributing area (hereafter SCA) which being retrieved from grid-based digital elevation models (DEMs) by flow direction algorithms and then applied to most landslide models (e.g., Barling et al., 1994; Dietrich et al., 1995; Casadei et al., 2003).

SCA is defined as the contributing area (also called upslope area or upslope contributing area) per unit width of contour. The contributing area represents the catchment area at any given point in space. The unit flow width in gridbased DEM is approximately the length of grid cell (Gallant and Wilson, 2000). This parameter representing the accumulated catchment area is preferably applied to various modelings about hydro-geomorphic processes (such as runoff, soil erosion and solute transport in subsurface) for considering stream power. Obviously, SCA is not only conceptually fundamental but also practical in model operation. Differences in algorithm-derived SCA have well been compared on ideal surface (e.g. Zhou and Liu, 2002; Florinsky, 1998; Wilson et al., 2000) or on hydrological simulation (Holmgren 1994; Quinn et al., 1995). However effects of algorithm-derived SCA on predicting slope failure have yet to be examined, particularly in subtropical mountainous watersheds with high rainfall and steep slope.

Published by Copernicus Publications on behalf of the European Geosciences Union. 
For quantifying the performance of FS prediction, a performance measure is required for calibration. Traditionally, success rate (SR), the ratio of rightly predicted landslide over the number of actual landslide, is up to now often used (Duan and Grant, 2000). However, traditional SR estimation ignores the component of stable cell prediction. This deficiency implies high SR can be achieved with the success in stable cell prediction being sacrificed. Huang and Kao (2006) proposed MSR (Modified Success Rate) which keeps SR while taking the predicted stable area into account and thus avoids over-prediction. Similarly, Rosso et al. (2006) also proposed a cell-based index by considering 4 combinations in error matrix, which is similar to kappa method. The two indexes are used in this study.

Taiwan, an island full of mountainous watersheds, is featured by steep slope and torrential rainfall brought by frequent typhoons (3-4 typhoons/year). Landslides often occur during or after typhoons. A small catchment, Erbu, which locates in central Taiwan, is studied. In order to calibrate a mean condition (see in 2.3), we collected 10-m DEMs, pre-typhoon NDVI (Normalized Difference Vegetation Index) themes from SPOT-5 imagery and post-typhoon landslide maps of the three typhoons with different rainfall intensities. Since all algorithms share the mean condition, the differences in FS prediction are mainly derived from algorithms.

This study aims to identify the differences of algorithminduced SCA values on the predictions of FS patterns and FS values by using SHALSTAB model, which is similar to SINMAP, proposed by Pack et al. (1998). Three algorithms: D8, Dinf, and FD8 holding different degrees of divergence are generated by using TAS (Terrain Analysis System, a powerful package designed for hydro-geomorphic applications by Lindsay, 2005). Results indicate SCA algorithm affects the landslide prediction significantly, especially for the slope gradient within 37-52 degree in our study.

\section{Materials and methods}

\subsection{SHALSTAB, soil wetness and flow algorithm:}

Hammond et al. (1992) proposed an infinite slope model. The original function of susceptibility of slope failure (factor of safety, FS) is implemented by:

$\mathrm{FS}=\frac{C+\left(Z \rho_{s}-h \rho_{w}\right) g \cos ^{2} \theta \cdot \tan \varphi}{\rho_{s} g Z \sin \theta \cdot \cos \theta}$.

The FS equation is well accepted in analyzing stability of shallow soils. The slope failure occurs when $\mathrm{FS}<1$, that is, the shear resistance is smaller than downslope shear stress. In the function, $C\left[\mathrm{~N} / \mathrm{m}^{2}\right]$ is the effective cohesion (the sum of soil and root cohesion), $g\left[9.81 \mathrm{~m} / \mathrm{s}^{2}\right]$ is the gravitational acceleration; $\rho_{s}$ and $\rho_{w}\left[\mathrm{~kg} / \mathrm{m}^{3}\right]$ are the densities of soil and water, respectively. $\theta$ stands for the slope gradient and $\phi$ is the internal friction angle. $Z[\mathrm{~m}]$ represents soil depth and $h[\mathrm{~m}]$ is the water table height above the slip surface. In the model, $h$ represents porewater pressure, which diminishes shear resistance with increasing rainfall. Estimating $h$ in different rainfall events turns out to be an important issue in many hydro-geomorphic applications.

In hydrological modeling, Beven and Kirkby (1979) and O'Loughlin (1986) assume that (1) lateral subsurface discharge at each point is in equilibrium with a steady state recharge (rainfall); (2) shallow lateral subsurface flow follows topographic gradients. Under the assumptions, the amount of subsurface runoff that flows through a cell should equal its respective SCA times the effective precipitation $(R)$ based on Darcy's law:

$R \cdot \mathrm{SCA}=K_{S} \cdot h \cdot \cos \theta \cdot \sin \theta$,

where $K_{S}$ is the saturated hydraulic conductivity. In any given point (cell), if the soil mantle is fully saturated $(h=Z)$, the maximum shallow subsurface flow will equal the transmissivity ( $T$, vertical integration of the saturated conductivity) times the gradient and the width of the outflow boundary (here the unit cell width, i.e. 1.0).

$T \cdot \sin \theta=K_{S} \cdot Z \cdot \cos \theta \cdot \sin \theta$

According to Eq. (2) and Eq. (3) the degree of soil wetness $(w=h / Z)$ can be obtained:

$w=\frac{h}{Z}=\min \left(\frac{R}{T} \frac{\mathrm{SCA}}{\sin \theta}, 1.0\right)$.

The soil wetness for a given storm, therefore, is determined by the hydrologic term $(R / T)$ and the topographic term $(\mathrm{SCA} / \sin \theta)$. When soil wetness exceeds 1.0 , saturated overland flow occurs. Besides, we simply remove the excess surface runoff instantaneously from the catchment and ignore it in further computations when soil is fully saturated as soil wetness >1.0 (Pack et al., 1998; Casadei et al., 2003). Thus the soil wetness is limited by 1.0 and can be incorporated into Eq. (1) as proposed by Montgomery and Dietrich (1994):

$\mathrm{FS}=\frac{C+\left(1-w \cdot \frac{\rho_{w}}{\rho_{s}}\right) \rho_{s} g Z \cos ^{2} \theta \cdot \tan \varphi .}{\rho_{s} g Z \sin \theta \cdot \cos \theta}$.

This slope failure equation is named SHALSTAB later (Dietrich and Montgomery, 1998). Incorporation of soil wetness into the original model allows calculation of FS at a given point (i.e. given topographic term) in any given hydrological term. The topographic term is affected by SCA algorithm.

In our literature review, more than eight algorithms have been proposed to determine flow directions and then calculate SCA. Three often-used flow direction algorithms are applied in this study, namely, D8, Dinf, and FD8. The D8 algorithm is developed by O'Callaghan and Mark (1984). This method designs water flow from a cell to the one with the lowest elevation among the eight nearest neighbor cells (Fig. 1a). Since water flow from several upslope cells may 
accumulate into a cell but only drains out to a single cell, this method can model convergent flow in valleys. However, it fails to model the flow divergence near ridge or hillslope areas (Zhou and Liu, 2002). To accommodate flow divergence, multiple flow directions (FD8) is then proposed by Freeman et al. (1991). However, FD8 often encounters over-dispersion (Fig. 1b). To reduce over-dispersion in FD8 and grid-bias, due to fixed grid orientation in D8, Tarboton (1997) proposes the infinite flow direction method (Dinf). This method is partly inspired by the aspect-driven algorithm (Lea, 1992). Only the two neighboring cells within the steepest facet can receive upslope flows, and the fractional flow is dependent on the slope angle on the facet (Fig. 1c). Among the three methods discussed above, the degree of divergence is FD8 $>$ Dinf $>$ D8 according to the number of receptor cell. The three SCA patterns are generated by TAS and introduced into SHALSTAB.

\subsection{Performance measure for landslide models}

Performance measure is crucial for any modeling work. Previous landslide susceptibility studies (Montgomery and Dietrich, 1994; Dietrich et al., 1995; Borga et al., 1998; Borga et al., 2002; Duan and Grant, 2000) used success rate (SR), defined as a ratio of how many actual landslide sites are rightly predicted, to evaluate the model performance. It is reasonable the SR adopted site-based unit to maintain the coherence of landslide although most model predictions using grid-based DEM provide cell-based results. However, SR does not include the success (or failure) in stable cell prediction which inherits in the model; thus, it precludes the detection of over-prediction of slope failure. To avoid overprediction, Rosso et al. (2006) develop the index by considering 4 combinations in error matrix (Rosso-Rulli-Vannucchi index $=$ rightly simulated unstable cells/observed unstable cells + rightly simulated unstable cells/simulated unstable cells + rightly simulated stable cells/observed stable cells + rightly simulated stable cells/simulated stable cells). The cell-based index is somewhat similar to kappa method and value higher than $50 \%$ are regarded as satisfying simulations.

On the other hand, Huang and Kao (2006) proposed an index, MSR, to evaluate the similarity between FS prediction and observed landslide map. MSR avoids over-prediction and maintains the coherence of landslide.

$\mathrm{MSR}=0.5 \frac{P L}{A L}+0.5 \cdot \frac{P S C}{A S C}$,

where $A L$ is total number of actual landslides, $P L$ is the number of rightly predicted landslides, $A S C$ is total number of actual stable cells and $P S C$ is rightly predicted stable cells.

In this equation landslide number instead of cell is used in performance calculation (a landslide usually contains more than one cell) for maintaining the coherence of landslide. However, cell is used for performance of stable area prediction. In this study, we use MSR to retrieve model parameters;

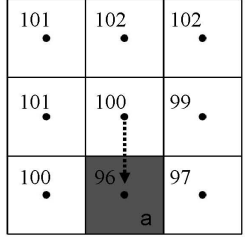

(a) D8 Scheme $\mathrm{a}=100 \%$

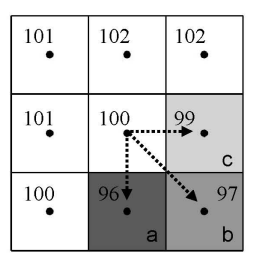

(b) FD8 Scheme $\mathrm{a}=65.6 \%, \mathrm{~b}=23.0 \%$, $\mathrm{c}=15.4 \%$

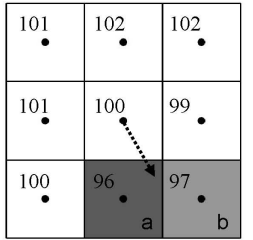

(c) Dinf Scheme $\mathrm{a}=57.1 \%, \mathrm{~b}=42.9 \%$
Fig. 1. The routing scheme of (a) single flow direction algorithm, D8; (b) multiple flow direction, FD8; and (c) Infinite flow direction, Dinf. The number in each cell indicates the elevation and the letters represent the flow fraction.

yet, we have comparisons by using both in quantifying the model performance (see Table 2).

\subsection{Parameter calibration}

Six essential parameters - soil depth, soil density, internal fraction angle, soil transmissivity, rainfall intensity and effective cohesion - are calibrated in SHALSTAB. Since the soil depth in Taiwan is usually shallow owing to the precipitous landscapes caused by torrential rainfall and significant tectonic uplift (Chen and Wu, 2006), we assume that soil depth and transmissivity are constant and spatially uniform as previously (Pack et al., 1998 and Huang et al., 2006). For determining hydrologic term, both rainfall intensity and duration are favorably considered for shallow landslide occurrence (Borga et al., 2002; Rosso et al., 2006). As using steady state approach, Montgomery and Dietrich (1994) suggest 24-h duration to yield FS predictions. However, in Taiwan most typhoons have rainfall durations for 36-60 h, thus, the peak 2-day rainfall intensity is taken (Huang et al., 2007). As effective cohesion, the sum of soil and root cohesion, is concerned, the colluvial soil is cohesionless that the soil cohesion is much less than root cohesion, which means effective cohesion is mainly determined by root cohesion or vegetation. Therefore, spatial effective cohesion due to seasonal variability (Duan and Grant, 2000) was suggested to obtain by using SPOT imagery (Rompaey et al., 2005). We followed similar approach; NDVI values retrieved from SPOT-5 (provided by Center for Space and Remote Sensing Research, National Central University) are used to configure the spatial pattern of effective cohesion. We define minimum and maximum effective cohesions $\left(C_{\min }\right.$ and $C_{\min }+$ $C_{\text {interval }}$, respectively) to transfer the full spectrum of NDVI value $(-1.0 \sim 1.0)$ into effective cohesion for each cell. On considering seasonality, individual pre-typhoon NDVI theme was applied (details in Huang et al., 2006).

Below we show the process of calibration to obtain the most satisfying parameter combination to represent the mean condition. Firstly, we set parameter ranges based on the previous studies and generate 1000 parameter combinations 


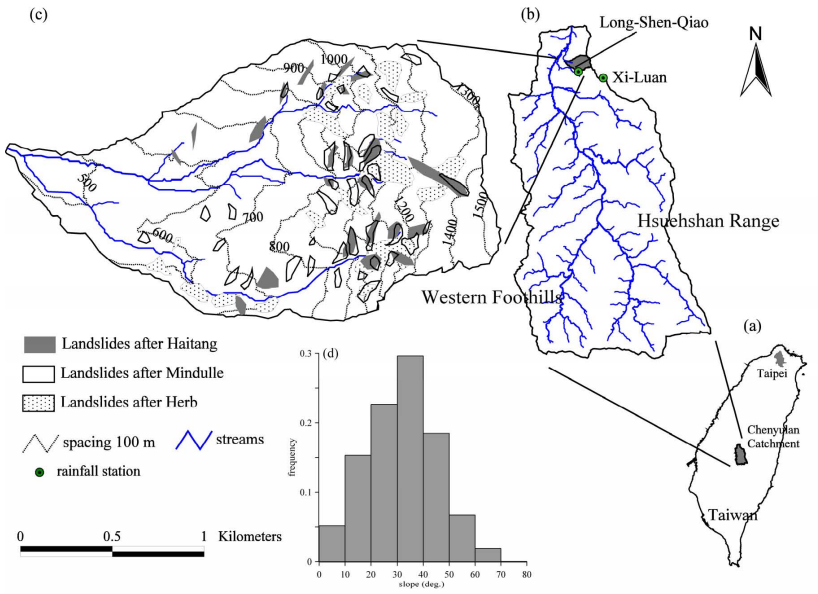

Fig. 2. The location and topography of Erbu watershed. (a) The location of Chenyulan catchment in Taiwan; (b) The stream networks and rainfall stations in Chenyulan catchment; (c) The topography, river networks and spatial pattern of landslides in Erbu watershed; all landslides triggered by the three typhoons: Herb, Mindulle, and Haitang are shown, and (d) The slope histogram in Erbu watershed.

by using uniform random number (Duan and Grant, 2000; Heuvelink, 1993). Three SCA themes are calculated based on the 10-m DEM (from Soil Water Conservation Bureau in Taiwan) in TAS. Secondly, the pre-typhoon NDVI themes are transferred into effective cohesion by the specific $C_{\min }$ and $C_{\text {interval }}$. Thirdly, we run SHALSTAB by using respective typhoon rainfall intensity. The peak 2-day rainfall intensities are 144.0, 248.0, and $327 \mathrm{~mm} /$ day, respectively, for typhoon Haitang, Mindulle, and Herb. Finally, these generated FS maps and their corresponding post-typhoon actual landslide maps are compared and evaluated by using MSR. This procedure gives us 9 MSR values for each combination run. We summarize the nine values as overall success rate and then rank to single out the most satisfying combination (i.e., the mean condition) with the highest overall success rate from 1000 simulations. This combination was used as a base to examine differences in soil wetness and susceptibility maps (FS maps) which result purely from algorithms.

\subsection{Study site}

Erbu is a subcatchment of Chenyulan River in central Taiwan (Fig. 2a). The Chenyulan Catchment is well-known for landslides and debris flows. The basin area is $443.6 \mathrm{~km}^{2}$ with elevations from 310 to $3952 \mathrm{~m}$ and a mean annual rainfall around $3000 \mathrm{~mm}$. The main stream of Chenyulan River separates the basin into two major geological zones, namely, the Western Foothills and the Hsuehshan Range (Fig. 2b). Erbu catchment locates in the Hsuehshan Range zone (Fig. 2c) which comprises lightly metamorphic rocks being full of fractured zones, and the reported values of the friction angle there varies from 35-40 degree (Lin and Lu, 2000; Lin and Jeng, 2000). The colluvial soil over the whole area is silty sand with roughly $0.5-2.5 \mathrm{~m}$ in thickness. Over $27 \%$ of the area is steeper than 40 degree and about $80 \%$ of it steeper than 20 degree, which indicates a precipitous landscape in this area (Fig. 2d). Forest occupies in the upper stream and steep slopes while arecas and bamboos are planted in the down stream and lower elevation areas. Two rainfall stations, Xi-Luan and Long-Shen-Qiao (data from Water Resource Agency), nearby the catchment recorded the rainfall intensity during the three typhoons.

Three typhoons, Herb (30 July to 7 August, 1996), Mindulle (1 July to 9 July, 2004) and Haitang (17 July to 25 July, 2005) are selected for case study. All three typhoons brought torrential rains triggering a number of landslides in the catchment (Fig. 2c). The paired aerial-photos (pretyphoon and post-typhoon) of the three typhoons are used to develop an inventory of landslide sites. Those aerial-pootos rectified and calibrated by the DEMs are used to delineate the landslide sites. The landslide sites in pre-typhoon photos are regarded as the remains of the historical landslides or outcrops. Meanwhile landslide sites in post-typhoon aerialphotos which are not shown in pre-typhoon aerial-photos are attributed to that typhoon and then are digitized. Through the subtraction, the outcrops and remains of historical landslides can be precluded. As a result, the landslide areas induced by Haitang, Mindulle, and Herb are $0.11,0.12$, and $0.22 \mathrm{~km}^{2}$, respectively. Most landslides induced by Mindulle and Haitang were checked in the field (Chung, 2005). Apparently, most landslide sites occur in steep slopes or near the initiation of channels. The fact that landslides often re-occur in similar locations strongly indicates that those areas are unstable at all times and deserve close attention.

\section{Results}

After calibration, the most satisfying combination holds parameter values: soil depth $=1.93 \mathrm{~m}$; bulk density $=$ $2.5 \mathrm{~g} / \mathrm{cm}^{3}$; internal fraction angle $=38.3$ degree; $C_{\min }=$ $8.70 \mathrm{kpa}$ and $C_{\text {interval }}=3.2 \mathrm{kpa}$; transmissivity $=4.28 \mathrm{~m}^{2} /$ day . As mentioned above, soil wetness is R/T (hydrological term) times $\mathrm{SCA} / \sin \theta$ (topographic term). In a given event, the hydrological term is fixed and soil wetness at a certain point is controlled by the SCA and slope gradient, consequently the FS value. Below, the frequency distributions of SCA values derived from algorithms are presented first and then followed by the spatial patterns of soil wetness and FS values.

\subsection{The frequency distributions of SCA derived from algo- rithms}

The frequency distributions of all SCA values derived from the three algorithms are illustrated in Fig. 3a. Total cell number in the watershed is 26345 . Seven categories from 0 to 70 degree at 10 degree interval are classified (Fig. 3b) to reveal 
Table 1. Soil wetness distributions derived from algorithms during different rainfalls.

\begin{tabular}{lccccccccc}
\hline Area (\%) & \multicolumn{3}{c}{ Haitang } & \multicolumn{3}{c}{ Mindulle } & \multicolumn{3}{c}{ Herb } \\
& \multicolumn{2}{c}{$144(\mathrm{~mm} /$ day $)$} & \multicolumn{2}{c}{248 (mm/day) } & \multicolumn{2}{c}{$327(\mathrm{~mm} /$ day $)$} \\
Soil & D8 & Dinf & FD8 & D8 & Dinf & FD8 & D8 & Dinf & FD8 \\
wetness & & & & & & & & & \\
\hline$<0.2$ & 1.9 & 0.5 & 0.0 & 0.0 & 0.0 & 0.0 & 0.0 & 0.0 & 0.0 \\
$0.2-0.4$ & 17.3 & 9.6 & 1.3 & 6.0 & 1.8 & 0.0 & 0.2 & 0.0 & 0.0 \\
$0.4-0.6$ & 13.2 & 11.0 & 4.4 & 10.5 & 6.1 & 0.7 & 7.5 & 2.5 & 0.0 \\
$0.6-0.8$ & 9.0 & 9.1 & 5.5 & 9.1 & 6.9 & 1.9 & 7.3 & 4.4 & 0.5 \\
$>0.8$ & 58.6 & 69.9 & 88.8 & 74.4 & 85.2 & 97.3 & 84.9 & 93.1 & 99.5 \\
\hline
\end{tabular}

Table 2. Simulation results and model performances for the three algorithms.

\begin{tabular}{cccccc}
\hline Scenario & PL $^{1}$ & $\begin{array}{c}\text { Predicted } \\
\text { unstable cell }\end{array}$ & ASC $^{2}$ & $\begin{array}{c}\text { MSR } \\
(\%)\end{array}$ & $\begin{array}{c}\text { Rosso-Rulli- } \\
\text { Vannucchi index (\%) }\end{array}$ \\
\hline Haitang (24, 1116)* & & & & & \\
D8 & 18 & 2465 & 23086 & 78.3 & 57.5 \\
Dinf & 18 & 2949 & 22657 & 78.3 & 58.3 \\
FD8 & 20 & 4032 & 21695 & 86.9 & 60.0 \\
Mindulle (39, 1245) & & & & & 62.8 \\
D8 & 31 & 3600 & 22108 & 81.6 & 63.4 \\
Dinf & 32 & 4188 & 51587 & 84.2 & 63.5 \\
FD8 & 33 & 5186 & 20656 & 86.8 & 62.1 \\
Herb (20, 2203) & & & & & 62.5 \\
D8 & 18 & 5457 & 19810 & 94.7 & 62.4 \\
Dinf & 18 & 6133 & 19226 & 94.7 & \\
FD8 & 18 & 6964 & 18476 & 94.7 & \\
\hline
\end{tabular}

$*(x, y): x$ means the landslide number, $y$ is the landslide in unit of cell (total cell in catchment: 26345).

${ }^{1} \mathrm{PL}$ is the number of rightly predicted landslide.

2 ASC is the number of rightly predicted stable cells.

the difference among the three algorithms within each category (Fig. 3c).

Figure 3a shows most cells hold low $\operatorname{Ln}(\mathrm{SCA})$ values. Consistency among methods appears at high $\operatorname{Ln}(\mathrm{SCA})$ condition while inconsistency occurs when $\operatorname{Ln}(\mathrm{SCA})$ values are lower than 8. Apparently, algorithms project SCA differences particularly for cells on hillslopes and areas near the ridge, which is prone to landslide occurrence.

For the entire watershed, peak occurrence of $\operatorname{Ln}(\mathrm{SCA})$ value in frequency distribution (Fig. 3a) falls in $\operatorname{Ln}(\mathrm{SCA}$ ) category of 2.5, 3.5 and 4.5 for D8, Dinf and FD8, respectively. The mean of $\operatorname{Ln}(\mathrm{SCA})$ for the entire watershed for D8, Dinf and FD8 are 3.95, 4.23 and 4.86, respectively. The most convergent algorithm gives the lowest mean Ln (SCA) for the entire watershed. Similar patterns can be found in different slope categories (Fig. 3c) that frequency distributions of $\operatorname{Ln}(\mathrm{SCA})$ skew toward higher value as algorithm divergence increases. Shifts in SCA frequency distribution, from lower to higher SCA values, obviously, lead to changes of es- timated soil wetness in watershed scale. On the other hand, standard deviations for D8, Dinf and FD8 are 1.76, 1.69 and 1.60 , respectively. The most divergent algorithm gives the lowest standard deviation. This smaller standard deviation is due to FD8 distributes water more divergently and thus produces more cells with moderate values of SCA at the cost of both small and large SCA values. This statistic description derived from DEM at watershed scale gives us an overall picture about the magnitude of potential difference in SCA.

Algorithm-derived SCA values are presented in scatter plots in Fig. 4 for comparison at cell to cell basis. Values from Dinf are used as reference. Since the D8 method always yields a "full" cell that flows to another, the SCA value obtained using the D8 method is an integer multiple of the cell number, which causes discontinuous scattering along the $\mathrm{y}$-axis (Fig. 4a). About $15 \%$ of the SCA values derived from D8 fall out of the reference field defined as over \pm 1.0 on a natural log scale, particularly, those values at lower side. D8 tends to give lower values compared to Dinf on hill slopes 


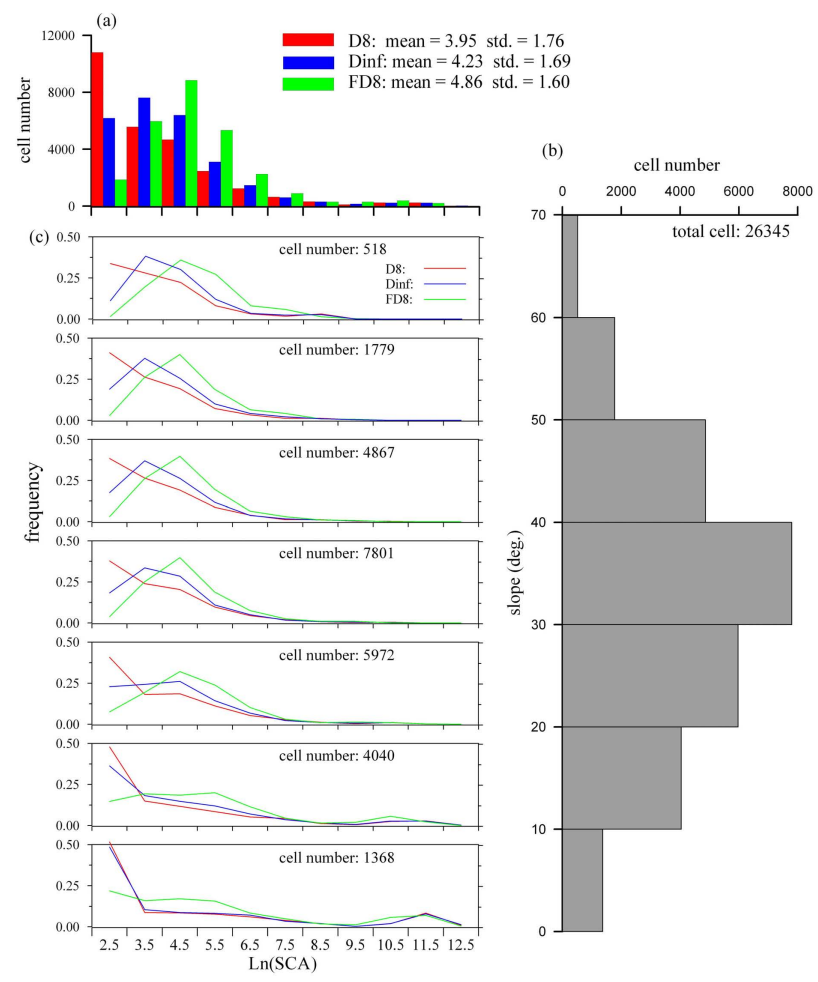

Fig. 3. The frequency distributions of $\operatorname{Ln}(\mathrm{SCA})$ driven from $\mathrm{D} 8$, Dinf, and FD8 (a). The histogram of slope in Erbu catchment (b) and the frequency distributions of the three algorithms in each slope category (c).
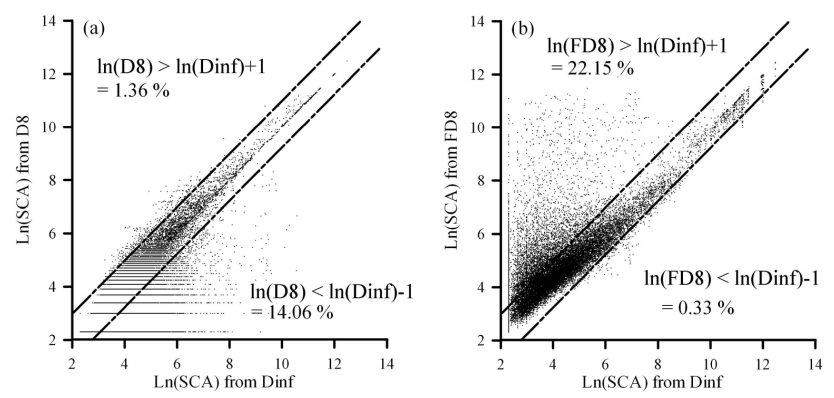

Fig. 4. (a) a scatter plot represents the $\operatorname{Ln}(\mathrm{SCA})$ from $\operatorname{Dinf}$ in $x$-axis and $\mathrm{Ln}(\mathrm{SCA})$ from D8 in y-axis; dash lines mean the difference larger or lower than 1.0 in $\mathrm{Ln}$ scale. The fractions of " $\ln (\mathrm{D} 8)>$ $\ln ($ Dinf $)+1$ " and " $\ln ($ D8 $)<\ln ($ Dinf $)-1$ " are shown; (b) a scatter plot represents the $\mathrm{Ln}(\mathrm{SCA})$ from Dinf in $\mathrm{x}$-axis and FD8 in y-axis and the fractions are also shown.

(around $14 \%$ in total). By contrary, approximately $22 \%$ of SCA values from FD8 fall beyond the reference field. Pooled Fig. 4a and Fig. 4b together, $\operatorname{Ln}(\mathrm{SCA})$ values derived from different algorithms may vary from 2.3 to 11.0 when we take the cells with $\operatorname{Ln}(\mathrm{SCA})$ of 4.0 by Dinf as references.
3.2 Watershed scale soil wetness derived from different algorithms

Area percentages categorized by different degree of soil wetness are shown in Table 1. Among the three typhoon cases, saturated area (defined as $>0.8$ soil wetness) gradually expands as rainfall intensifies. Under the rainfall of $327 \mathrm{~mm} /$ day, the proportions of saturated area surge to $84.9 \%$ for D8, 93.1\% for Dinf, and 99.5\% for FD8, respectively. It means that the watershed is almost fully saturated. Among the algorithms, the more divergent algorithm causes the larger saturated area. For example, the proportions of saturated area are 58.6, 69.9 and $88.8 \%$, respectively, for D8, Dinf and FD8 in the case of $144 \mathrm{~mm} /$ day. The differences in saturated area between D8 and FD8 are as high as 30.2\% and $14.4 \%$, respectively, at $144 \mathrm{~mm} /$ day and at $327 \mathrm{~mm} /$ day. This range of rainfall intensity is usual as typhoon strikes Taiwan (Huang et al., 2007) indicating soil wetness estimation in the range deserve attentions when considering rainfall intensity in landslide susceptibility models.

\subsection{The simulated FS maps and model performance}

The nine FS predictions produced by three algorithms for the three typhoons (different rainfall intensity and effective cohesion) are presented in Fig. 5 and quantitative simulated results are shown in Table 2. Those FS spatial patterns are also overlaid with post-typhoon landslide maps for comparison in Fig. 5. Landslides triggered by Haitang, Mindulle and Herb were 24, 39 and 20, while those landslides occupied 1116, 1245, and 2203 cells, respectively (Table 2). Apparently, individual landslide is much larger in scale in Herb case.

Model results show consistency between landslide cell numbers and peak 2-day rainfall intensity, particularly, between Haitang and Herb, revealing that unstable cell number is a function of rainfall intensity. Note that Haitang and Mindulle have similar numbers of predicted unstable cell under different rainfall intensity (Table 2). This is due to higher values of effective cohesion derived from pre-Mindulle NDVI map. On the other hand, numbers of predicted unstable cell are significantly different among three algorithms. Unstable cell number increases as algorithm divergence and rainfall intensity increase. In unit of landslide (rather than unstable cell), the number of rightly predicted landslides is almost the same among algorithms in individual case (Table 2). In terms of landslide site simulation, model performance is satisfying regardless SCA algorithms. The model performances measured by MSR and Rosso-Rulli-Vannucchi index index are satisfying and shown for comparison (Table 2). Both measures indicate SHALSTAB performs promising. Apparently, both MSR and Rosso-Rulli-Vannucchi index index can not discriminate specific differences in unstable cell prediction caused by three algorithms. This is due to the fractional 

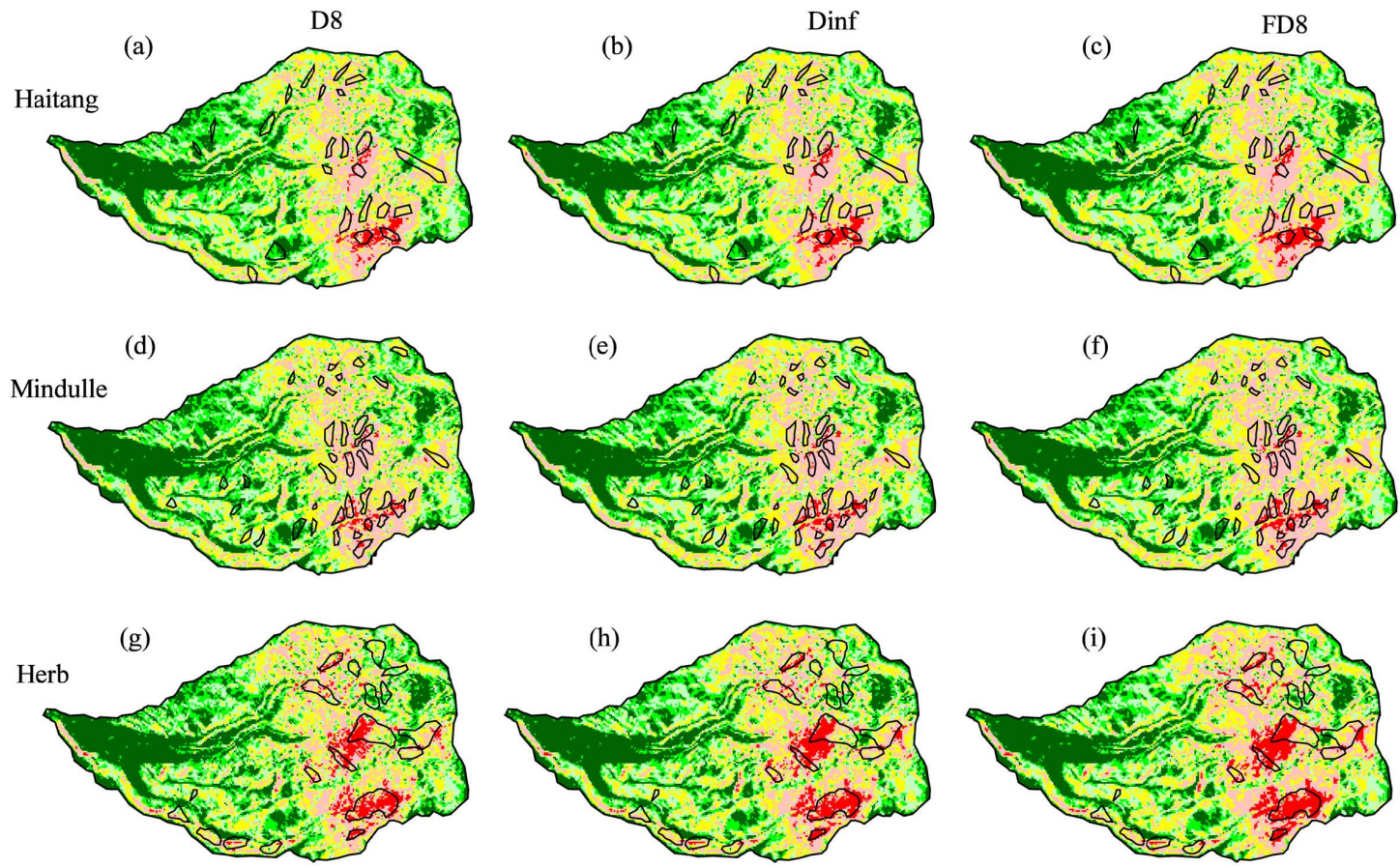

FS

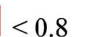

$0.8 \sim 1.0$

$1.0 \sim 1.2$
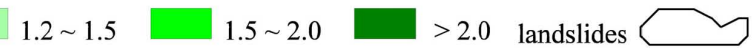

Fig. 5. FS spatial patterns derived from the three algorithms in the three typhoons and actual landslides induced by the three typhoons are also marked.

occupation of stable cell is much higher than that of unstable cell in the studied watershed (see Sect. 2.2).

\subsection{Cell-based differences in FS value among algorithms}

The identification of unstable cell is based on $\mathrm{FS}=1.0$, which has a clear definition and physical meaning, thus, $\mathrm{FS}=1.0$ is regarded as the only criterion of identifying unstable cell though various criterion (e.g. $F S=0.9$ or 1.1 ) and fuzzy variable had been applied (Freer et al., 2004).

The compositions of unstable areas obtained by using various algorithms are examined in pairs (Fig. 6). Paired Fig. 6a and b; Fig. 6c and d; Fig. 6e and Fig. 6f, display the Haitang, Mindulle and Herb cases, respectively. The relative difference ratio (relative to Dinf) in each cell is defined as (FS by $A_{\text {method }}$ - FS by Dinf)/(FS by Dinf). Based on this calculation, the horizontal line indicates identical values between algorithms. Above the horizontal line will be cells with higher FS values by $A_{\text {method }}$ and vice versa. To elucidate interdifferences between algorithms we draw demarcation lines to differentiate inconsistent values. The vertical solid line (red line in Fig. 6) refers to cells with FS=1.0 by Dinf, thus, cells on the left are unstable. The dashed curve (green curve

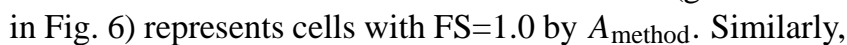
on the left of green curve will be unstable cells. Therefore, four classes of outcome are identified: I: cell by Dinf is unstable, but stable by $A_{\text {method }}$; II: unstable by both methods;
III: cell by Dinf is stable, but unstable by $A_{\text {method }}$ IV: stable by both methods. In between the red line and green curve (i.e., Zone I and III) are cells with inconsistent FS values.

FS values derived by D8 commonly exceed those by Dinf except cells with concentrated flow paths by D8 (Fig. 6a, c and e). Therefore, most cells have positive relative difference ratios. By contrast, FD8 generally give lower FS values compared to Dinf (Fig. 6b, d and f). Although the unstable area occupies a small part of the whole watershed, this small part represents a major concern in hazard management. Meanwhile, predicted unstable cells by Dinf are the sum of zone I and II which is set to $100 \%$ for comparison. Figures $7 \mathrm{a}, \mathrm{c}$ and e show that the unstable area by D8 shrink $-16.4,-14.0$, and $-11.0 \%$ of the reference area in Haitang, Mindulle and Herb, respectively. In contrast, the unstable areas obtained by FD8 are 36.7, 23.8 and $13.5 \%$ larger than the reference area in Haitang, Mindulle and Herb, respectively (Fig. 6b, d and $\mathrm{f}$ ). The inconsistency among the predictions of unstable area derived from the D8 and FD8 may vary from -16.4 to $36.7 \%$ in relation to the unstable area derived from Dinf.

In the three typhoon cases, we also found the inconsistency in the relative difference ratio increases as the rainfall intensity increases. The relative difference ratio between D8 and Dinf may vary from -0.17 to +0.34 , from -0.15 to +0.24 and from -0.09 to +0.19 in Herb, Mindulle and Haitang, respectively, when FS=1.0 by Dinf. The relative difference 

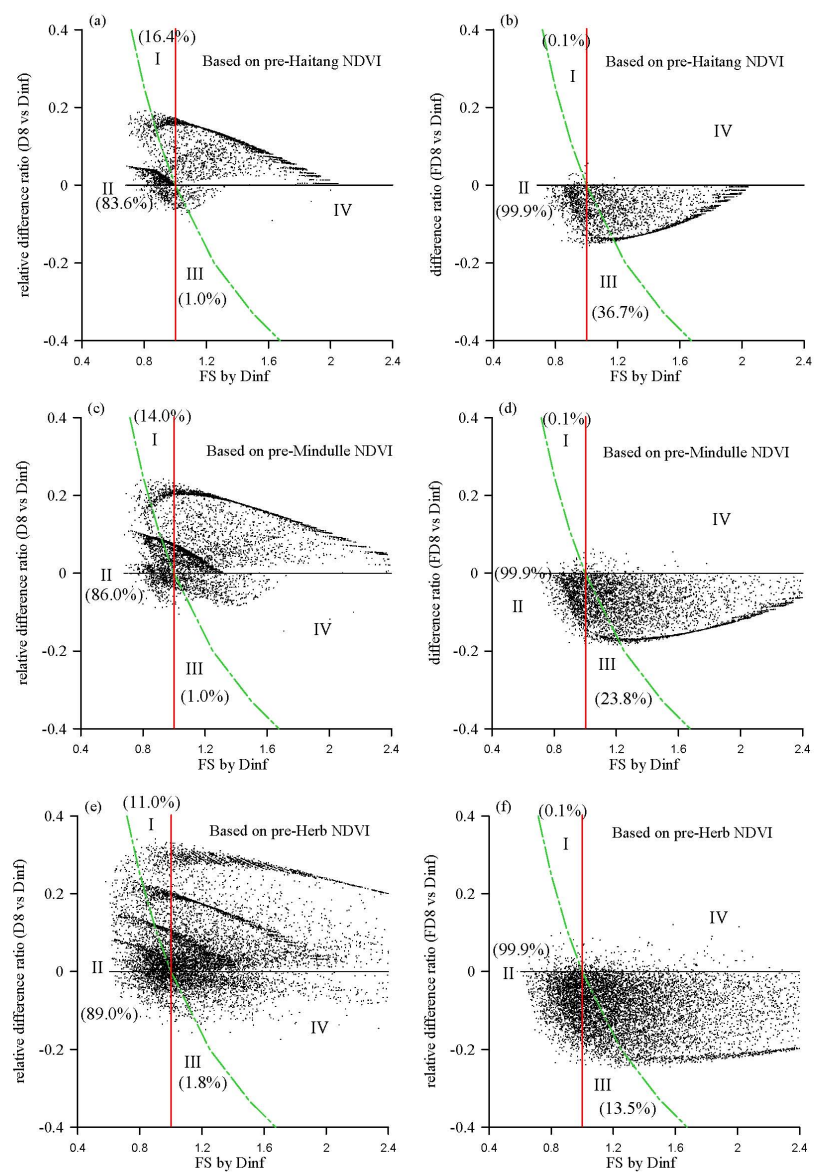

Fig. 6. The scatter plots of FS values derived from different algorithms. Relative difference ratio is defined as (FS by $A_{\text {method }}-$ FS by Dinf)/ (FS by Dinf). Zone I: $A_{\text {method is stable, but Dinf is unsta- }}$ ble; Zone II: both two methods are unstable; Zone III: Dinf is stable but $A_{\text {method }}$ is unstable; Zone IV: both of the two methods are stable. Zone I and II is the total predicted unstable cells by Dinf and set to $100.0 \%$ for comparison. (a) the FS values by D8 and Dinf in Haitang case (b) the FS values by FD8 and Dinf in Haitang case (c) the FS values by D8 and Dinf in Mindulle case (d) the FS values by FD8 and Dinf in Mindulle case (e) the FS values by D8 and Dinf in Herb case (f) the FS values by FD8 and Dinf in Herb case.

ratios between FD8 and Dinf possibly fluctuate from -0.25 to +0.12 , from -0.19 to +0.06 and from -0.16 to +0.06 , respectively, when FS=1.0 in Dinf. Pool together, FS values based on different algorithms in three events fluctuate from -0.25 to 0.34 at $\mathrm{FS}=1.0$ by Dinf. In other words, the variation that FS values may vary from 0.75 to 1.34 actually confuses the judgment when we obtain the predictions by different algorithms.

\section{Discussion}

Since the slope gradient, SCA, and rainfall intensity are the most important factors in determining landslide potential, below we discuss in details the correlations among the three variables.

\subsection{Rainfall intensity and unstable area in watershed}

In Results, we present differences in SCA calculation among algorithms and their effects on soil wetness and unstable area predictions in the three typhoons. Both saturated area and the percent cover of unstable cell show positive correlation with rainfall intensity. However, rainfall effect on landslide prediction is not linear and NDVI-themes in the three cases may obscure SCA effects. Based on the mean condition and respective NDVI-theme, we simulate proportional occupation of unstable cell over a full range of rainfall intensity from 0 to $1200 \mathrm{~mm} /$ day at an interval of $50 \mathrm{~mm} /$ day (Fig. 7). Those simulations provide a complete picture about effects from NDVI and rainfall intensity.

Among the three methods, FD8 creates the highest percentage of unstable area over full scale rainfall intensity, meanwhile, the percentage of unstable area from FD8 reaches plateau $(\sim 20 \%$ coverage in Haitang and Mindulle; $\sim 25 \%$ coverage in Herb) more rapidly compared to the other two methods (upper panels in Fig. 7). The relative size of predicted unstable area is consistent with the degree of algorithm divergence. Rapid saturation of the entire watershed is obviously due to higher SCA values derived from FD8. The difference in upper bound of unstable area coverage is resulted from NDVI-theme, that is, effective cohesion.

In the three typhoon cases, algorithm-generated difference in absolute unstable area coverage (percent watershed area) is around 6\% (upper panels in Fig. 7). Compared to Dinf, FD8 always gives higher coverage of predicted unstable area. By contrast, D8 gives lower coverage areas. The absolute difference in predicted unstable area with respect to Dinf (middle panels in Fig. 7) ranges from $\sim-3 \%$ to $+4 \%$ (percent watershed area). The maximum absolute difference appears around rainfall intensity of $\sim 200 \mathrm{~mm} / \mathrm{day}$. On the other hand, the relative difference (compared to Dinf) ranges from -15\% to as high as $+40 \%$ (lower panels in Fig. 7). The overall relative deviation among methods is as high as $60 \%$. Toward higher and lower rainfall intensities, algorithm-induced relative deviation decreases significantly. The maximum absolute and/or relative differences in landslide prediction occurs around the condition of $100-300 \mathrm{~mm} /$ day regardless NDVItheme. This rainfall intensity range is very common in subtropical mountainous region revealing the significance of algorithm effect on landslide prediction.

Note that $\sim 2.6 \%$ (NDVI affects little on this value) of the catchment area (upper panels in Fig. 7) is predicted to be unstable even rainfall intensity is zero no matter which algorithm is applied. Such rainfall independent unstable areas 

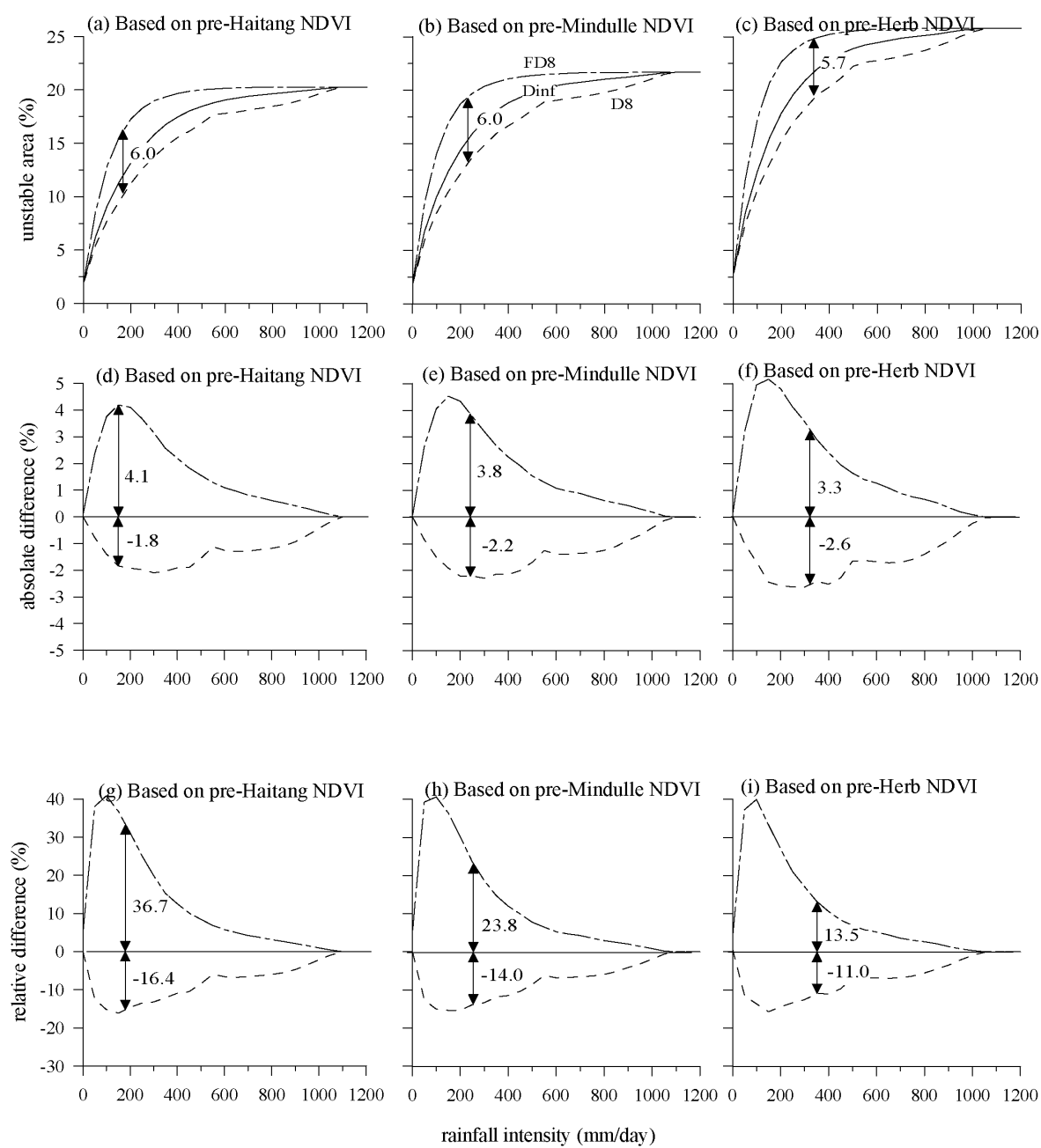

Fig. 7. Curves of simulation over full scale rainfall intensities based upon different NDVI-themes from (a, d, g) Haitang, (b, e, h) Mindulle and $(\mathbf{c}, \mathbf{f}, \mathbf{i})$ Herb. Upper panels $(\mathrm{a}, \mathrm{b}$ and $\mathrm{c}$ ) are for unstable area coverage (in \% watershed). Middle panels (d, e and $\mathrm{f}$ ) are for absolute difference (compared to Dinf) in unstable area coverage (in \% watershed). Lower panels ( $\mathrm{g}$, h and i) are for relative difference (compared to Dinf). Arrows indicate event rainfall and numbers mark the range of deviation between FD8- and D8-derived simulations.

are almost determined by topographic term. However, when rainfall intensity approaches $600 \mathrm{~mm} /$ day, algorithm-induced relative difference reduces to $\sim 10 \%$ since the entire watershed is nearly saturated. In Taiwan and many subtropical regions, $100-300 \mathrm{~mm} /$ day brought by single typhoon is usual; unfortunately, within this range of rainfall intensity algorithm effect is most significant.

\subsection{Algorithm effect on FS prediction in mountainous ter- rain}

The theoretical diagram among slope, $\operatorname{Ln}(\mathrm{SCA})$, rainfall intensity (see Eq. 5) and model-derived FS values of 1 (criteria for landslide) are shown in Fig. 8. In this diagram, we identify the field of rainfall-sensitive zone based on the mean of pre-Mindulle NDVI theme. Cells locate in this zone are affected by hydrologic term. Outside this zone will be uncon- ditionally stable and unconditionally unstable zones. Unconditionally unstable means cells in dry condition still tend to fail all the time due to the steep slope even the soil wetness is zero. By contrast, cells in unconditionally stable zone will not fail even the soil mantle is saturated due to gentle slope and effective cohesion.

When the effective cohesion is zero (soil is cohesionless and no root cohesion), the lower bound of unconditionally unstable zone is identical to friction angle ( $\phi=38.3$ degree $)$ and the upper bound of unconditionally stable zone equals to 25.4 degree $\left(\rho_{w} / \rho_{s}=0.6\right.$ and $\phi=38.3$ degree; Eq. 5). However, the effective cohesion contribution (the mean NDVI value is 0.49) in Mindulle case generates 37.4 and 51.8 degree, respectively, for slope boundaries of rainfall-sensitive zone (Fig. 8). 


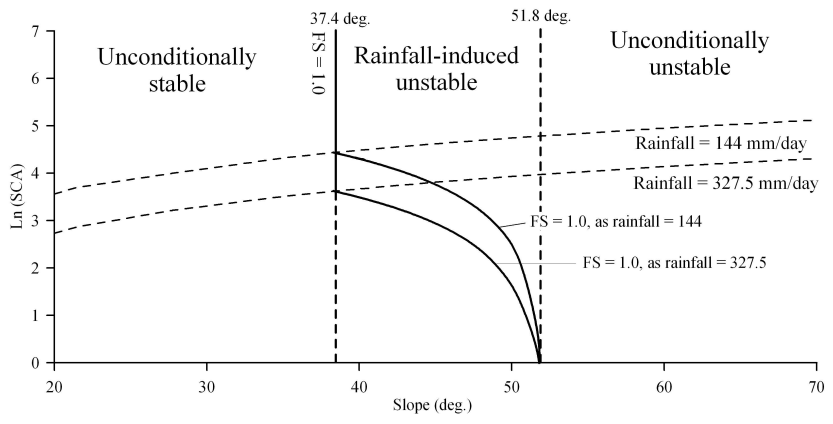

Fig. 8. The theoretical relationship between slope gradient, rainfall intensity $\mathrm{Ln}$ (SCA) and FS. The cross dot is a specific point at 40 degree of slope and the three SCA values are labeled.

Previous study indicates the importance of plant roots which provides stress resistance may increase $40 \%$ the value of the friction angle (Rosso et al., 2006; Montgomery and Dietrich 1994), however the measurement and aggregation of root strength on slope stability is not clearly understood (Schmidt et al., 2001). Many factors such as species, diameter of root and density affect effective cohesion reciprocally (Bischetti et al., 2005). Vegetation map or NDVI themes is regarded as a good way to simplify and vividly represent the effective cohesion (Borga et al., 2002). The vegetation effect in this study increases $60 \%$ the value of the friction angle to stress resistance, which makes a lower unconditionally unstable area (2.6\%, see Fig. 6b) compared to that in previous studies ( $15 \%$; see Rosso et al., 2006; Montgomery and Dietrich 1994).

In the rainfall-sensitive zone, hydrological term plays a major role determining the FS value. In Fig. 8, upper curved dash line represents the soil wetness $=1.0$ at the rainfall intensity of $144 \mathrm{~mm} /$ day. According to Eq. (5), we also obtain the curve of FS=1 (upper solid curve in Fig. 8) in the rainfallsensitive zone. Cells above the solid curve hold FS $<1.0$ (i.e., landslide occurs). Similarly, we make curves for rainfall intensity of $327 \mathrm{~mm} /$ day. In this theoretical diagram, curve of $\mathrm{FS}=1$ lowers down as rainfall intensity increases. Certainly, the larger hydrologic term expand the coverage of unstable zone until the entire catchment is fully saturated (seeing Sect. 4.1).

Based on our simulation and theoretical relationship, FS prediction of cells in between slope from 37.4 to 51.8 should be judged cautiously. As mentioned in 3.1, algorithms project SCA differences particularly for cells on hillslopes (20\% area of study catchment falls in between 40 to 50 degree, Fig. 3) and around $20 \%$ cells of $\operatorname{Ln}($ SCA) values are significantly inconsistent. It highlights the importance of algorithm effects on landslide modeling in mountainous watersheds. Besides, different hydrologic term $(\mathrm{R} / \mathrm{T})$, which causes different rainfall-induced unstable coverage, has been widely coupled with the concept of intensityduration-frequency to demonstrate the relationship between landslide magnitude and rainfall return period (e.g. Barling et al., 1994; Borga et al., 2002; Rosso et al., 2006). Apparently, algorithm selection may alter landslide magnitudes derived by rainfall return periods as well. We conclude that in any comparison among SCA-related landslide models or engineering application of rainfall return period analysis must base on the same algorithm to obtain comparable results. The Dinf is an intermediate algorithm among the three, we do not evaluate their goodness; however, previous studies by Sorensen et al. (2006) and Endreny and Wood (2003) suggested using Dinf for SCA calculation based on their in-situ observations by chemical tracers.

\section{Conclusions}

Landslide prevention is an important issue for land management particularly in mountainous watersheds. We demonstrate the influence of SCA algorithm on landslide model outputs. The frequency distributions of SCA value at watershed scale by the three algorithms (FD8, Dinf, and D8) reveal that the most divergent algorithm (FD8) can generate the highest mean and the lowest standard deviation of SCA. The higher mean of SCA causes relatively rapid saturation as rainfall intensity increases. The smaller standard deviation of SCA results in the more homogeneous pattern of estimated soil wetness. Meanwhile, the greatest difference of SCA in space is on the hillslopes, which occupies $\sim 27 \%$ of entire watershed. Such difference significantly affects prediction of factor of safety (FS).

Simulations of SCA algorithm effect on unstable area coverage and FS value predictions reveal potential algorithmgenerated deviations over a full rainfall spectrum. Relative to the Dinf, the unstable areas by D8 and FD8 can reach $\sim 17 \%$ lower and $\sim 41 \%$ higher, respectively, around rainfall intensity of $100-300 \mathrm{~mm} /$ day, which is usual in subtropical mountainous region. Based on theoretical diagram among slope, rainfall intensity, $\operatorname{Ln}(\mathrm{SCA})$ and $\mathrm{FS}$ we derive the rainfallsensitive zone for FS prediction. The diagram reveals that FS prediction is very sensitive to $\operatorname{Ln}(\mathrm{SCA})$ changes in slope from 37 to 52 degree, which occupies a significant portion ( $\sim 21 \%$ in this study) in analogue mountainous watersheds. We conclude that any comparison among SCA-related landslide models or engineering application of rainfall return period analysis must base on the same algorithm to obtain comparable results.

Acknowledgements. The authors would like to thank the National Science Council of Taiwan, for financial support (No. NSC 95-2116-M-001-001). Many thanks must be given to the two anonymous reviewers and their constructive comments. Besides, we also deeply appreciate N. Otto for the kind assistance.

Edited by: T. Glade

Reviewed by: two anonymous referees 


\section{References}

Barling, R. D., Moore, I. D., and Grayson, R. B.: A quasi-dynamic wetness index for characterizing the spatial distribution of zones of surface saturation and soil water content, Water Resour. Res., 30, 1029-1044, 1994.

Beven, K. and Kirkby, M. J.: A physically based, variable contributing area model of basin hydrology, Hydrol. Sci. Bull., 24, 43-69, 1979.

Bischetti, G. B., Chiaradia, E. A., Simonato, T., Speziali, B., Vitali, B., Vullo, P., and Zocco, A.: Root strength and root area ratio of forest species in Lombardy (Northern Italy), Plant Soil., 278, 11-22, 2005.

Borga, M., Dalla Fontana, G., Ros, D. D., and Marchi, L.: Shallow landslide hazard assessment using a physical based model and digital elevation data, Environ. Geol., 35, 81-88, 1998.

Borga, M., Dalla Fontana, G., and Cazorzi, F.: Analysis of topographic climatic control on rainfall-triggered shallow landsliding using a quasi-dynamic wetness index, J. Hydrol., 268, 56-71, 2002.

Burton, A. and Bathurst, J. C.: Physically based modeling of shallow landslide sediment yield at a catchment scale, Environ. Geol., 35, 89-99, 1998.

Casadei, M., Dietrich, W. E., and Miller, N. L.: Testing a model for predicting the timing and location of shallow landslide initiation in soil-mantled landscapes, Earth Surf. Proc. Land., 28, 925-950, 2003.

Chen, S. C. and Wu, C. H.: Slope stabilization and landslide size on Mt. 99 peaks after ChiChi earthquake in Taiwan, Environ. Geol., 50(5), 623-636, 2006.

Chung, Y. Y.: Comparison on the characteristics of rainfall-induced landslide before and after the Chi-Chi earthquake. Master Thesis, National Taiwan University, Taipei, Taiwan, 2005 (in Chinese).

Dietrich, W. E., Reiss, R., Hsu, M. L., and Montgomery, D. R.: A process-based model for colluvial soil depth and shallow landsliding using digital elevation data, Hydrol. Process., 9 383-400, 1995.

Dietrich, W. E. and Montgomery, D. R.: SHALSTAB: A digital terrain model for mapping shallow landslide potential, http: //socrates.berkeley.edu/ $\sim$ geomorph/shalstab, 1998.

Duan, J. and Grant, G. E.: Shallow Landslide Delineation for Steep Forest Watersheds Based on Topographic Attributes and Probability Analysis, in: Terrain Analysis - principles and applications, edited by: Wilson, J. P. and Gallant, J. C., Wiley, 311-329, 2000

Endreny, T. A. and Wood, E. F.: Maximizing spatial congruence of observed and DEM-delineated overland flow networks, Int. J. Geographic Inf. Sci., 17(7), 699-713, 2003.

Florinsky, I. V.: Accuracy of local topographic variables derived from digital elevation models, Int. J. Geographic Inf. Sci., 12, 47-61, 1998.

Freeman, G. T.: Calculating catchment area with divergent flow based on a regular grid, Comput. Geosci., 17, 413-422, 1991.

Freer, J. E., McMillan, H., McDonnell, J. J., and Bevev, K.: Constraining dynamic TOPMODEL responses for imprecise water table information using fuzzy rule based performance measures, J. Hydrol., 291(3-4), 254-277, 2004.

Gallant, J. C. and Wilson, J. P.: Primary Topographic Attributes, in: Terrain Analysis - principles and applications, edited by: Wilson, J. P. and Gallant, J. C., Wiley, 51-85, 2000.
Hammond, C. D., Hall, D., Miller, S., and Swetik ,P.: Level I Stability Analysis (LISA): Documentation for version 2.0. Ogden, UT: United States Department of Agriculture, Forest Service, Intermountain Research Station General Technical Report No. 285 , 1992.

Heuvelink, D.G.: Error propagation in quantitative spatial modeling: Application in GIS, PhD thesis, Utrecht University, Netherlands, 1993.

Holmgren, P.: Multiple flow direction algorithms for runoff modeling in grid-based elevation models: an empirical evaluation, Hydrol. Process., 8, 327-334, 1994.

Huang, J. C. and Kao, S. J.: Optimal estimator for measuring landslide model efficiency, Hydrol. Earth Syst. Sci., 10, 957-965, 2006, http://www.hydrol-earth-syst-sci.net/10/957/2006/.

Huang, J. C., Kao, S. J., Hsu, M. L., and Lin, J. C.: Stochastic procedure to extract optimal input parameter combinations and to construct integrated landslide occurrence map: An example of mountainous watershed in Taiwan, Nat. Hazards Earth Syst. Sci., 6, 803-815, 2006, http://www.nat-hazards-earth-syst-sci.net/6/803/2006/.

Huang, J. C., Lee, T. Y., and Kao, S. J.: Simulating typhooninduced storm hydrographs in subtropical mountainous watershed: An integrated 3-layer TOPMODEL. Submitted to Environmental Modeling and Assessment, 2007.

Lea, N. J.: An aspect-driven kinematic routing algorithm, in: Overland Flow: Hydraulics and Erosion Mechanics, edited by: Parsons, A. J. and Abrahams, A. D., UCL Press, 393-407, 1992.

Lin, M. L. and Lu. Y. H.: Construction of GIS and Database for Debris Flow Potential Study of Chen-You-Lan River Watershed", Proceedings, the 17th International Symposium on Automation and Robotics in Construction, 645-650, 2000.

Lin, M. L. and Jeng, F. S.: Characteristics of hazards induced by extremely heavy rainfall in central Taiwan - Typhoon Herb, Eng. Geol., 58, 191-207, 2000.

Lindsay, J. B.: The Terrain Analysis System: A tool for hydrogeomorphic applications, Hydrol. Process., 19, 1123-1130, 2005.

Montgomery, D. R. and Dietrich, W. E.: A Physically-Based Model for the Topographic Control on Shallow Landsliding, Water Resour. Res., 30, 1153-1171, 1994.

O'Callaghan, J. F. and Mark, D. M.: The extraction of drainage networks from digital elevation data, Computer Vision, Graphics and Image Processing, 28, 323-344, 1984.

O'Loughlin, E. M.: Prediction of surface saturation zones in natural catchments by topographic analysis, Water Resour. Res., 22, 794-804, 1986.

Pack, R. T., Tarboton, D. G., and Goodwin, C. N.: The SINMAP Approach to Terrain Stability Mapping, Congress of the International Association of Engineering Geology, Vancouver, British Columbia, Canada 21-25 September, 1998.

Quinn, P. F., Beven, K. J., and Lamb, R.: The $\ln (\mathrm{a} / \tan \beta)$ index: How to calculate it and how to use it within the topmodel framework, Hydrol. Process., 9(2), 161-182, 1995.

Rompaey, A. V., Bazzoffi, P., Jones, R. A. A., and Montanarella, L.: Modeling sediment yields in Italian catchments, Geomorphology, 65, 157-169, 2005.

Rosso, R., Rulli, M. C., and Vannucchi, G.: A physically based model for the hydrologic control on shallow landsliding, Water 
Resour. Res., 42, W06410, doi:10.1029/2005WR004369, 2006.

Schmidt, K. M., Roerinf, J. J., Stock, J. D., Dietrich, W. E., Montgomery, D. R., and Shaub, T.: Root cohesion variability and shallow landslides susceptibility in the Oregen Coast Range, Can. Geotech. J., 38(1), 995-1024, 2005.

Sorensen, R., Zinko, U., and Seibert, J.: On the calculation of the topographic wetness index: evaluation of different methods based on field observations, Hydrol. Earth Syst. Sci., 10, 101112, 2006, http://www.hydrol-earth-syst-sci.net/10/101/2006/.

Tarboton, D. G.: A New Method for the Determination of Flow Directions and Contributing Areas in Grid Digital Elevation Models, Water Resour. Res., 33(2), 309-319, 1997.
Wilson, J. P., Repetto, P. L., and Snyder, R. D.: Effect of data source, grid resolution, and flow-routing method on computed topographic attributes. In Terrain Analysis - principles and applications, Wilson, J. P. and Gallant, J. C., Wiley, 133-161, 2000.

Wu, W. and Sidle, R. C.: A distributed slope stability model for steep forested basins, Water Resour. Res., 31, 2097-2110, 1995.

Zhou, Q. and Liu, X.: Error assessment of grid-based routing algorithms used in hydrological models, Int. J. Geographical Inf. Sci., 16, 819-842, 2002. 